\title{
DA GUERRA DA MARIA ANTONIA AO CURSO DE CIÊNCIA, TECNOLOGIA E MOVIMENTOS SOCIAIS
}

\author{
Leda Maria Caira Gitaby \\ Elaine Hipólito dos Santos Costa
}

"To live in different countries get me the ability to see Braqil in a nev light on my return, and, in the beginning, the paradox of feeling a foreigner in my country. Little by little, through my research and teaching activities, in which I bave sought shelter, devoting myself to understand the recent bistory of my country and continent, I bave found that the magical realism of Latin-American literature is much more realistic than magical. Countries of the future with no memory from the past, we go on repeating the cycles of our "Hundred Years of Solitude", so well portrayed by Gabriel Garcia Márquez:" (Leda Gitahy, 2000)

RESUMO: Utilizando como bibliografia ${ }^{1}$ Hobsbawn e a trilogia de Castells, pretendemos entender porque, na chamada Sociedade da Informação a memória se perdeu. Existem correntes e contra correntes no sentido da perda ou da recuperação da memória coletiva. $A$ hipótese é que a Revolução Conservadora que se inicia na década de setenta $\mathrm{c}$ a concentração e controle dos meios de comunicação de massa, forjou esta perda da memória coletiva sobre nossa própria história. As imagens de queimas de livros $\mathrm{c}$ bibliotecas $\mathrm{em}$ muitas fases da história da humanidade agora não são necessárias. Basta deletar os arquivos ou abandoná-los em computadores velhos.

'O Ementa do Curso "Ciência, 'Tecnologia e Movimentos Sociais" cstá no fim do artigo, como ancxo, juntamente com a bibliografia utilizada. 
PALAVRAS-CHAVE: memória; sociedade da informação; movimento estudantil; ano de 1968; Maria Antônia.

\begin{abstract}
Using literature as Hobsbawm and trilogy Castells, we want to understand why, in so-called Information Society in memory lose. There are currents and cross currents in the sense of loss or recovery of collective memory. The hypothesis is that the Conservative Revolution which began in the seventies and the concentration and control of the means of mass communication, forged from the loss of collective memory about our own history. The images of burning of books and libraries in many phases of human history are not now necessary. Just delete the files or leave them in old computers.
\end{abstract}

KEYWORDS: memory; information society; student movement; year 1968; Maria Antonia.

RÉSUMÉ: Basé sur l'utilisation de la littérature comme Hobsbawm et la trilogie Castells, nous voulons comprendre pourquoi, dans la société de l'information la mémoire est perdue. Il ya des courants et contre-courants dans le sens de perte ou de récupération de la mémoire collective. L'hypothèse est que la révolution conservatrice qui a commencé dans les années soixante-dix et de la concentration et le contrôle des moyens de communication de masse, forgé cette perte de la mémoire collective sur le notre propre histoire. Les images de brûler les livres et les bibliothèques dans les nombreuses phases de l'histoire humaine ne sont pas actuellement nécessaires. Il suffit de supprimer les fichiers ou les abandonner dans de vieux ordinateurs.

MOTS-CLÉ: memoire; société d'information; mouvement ćtudiant; l'année 1968; Maria Antônia

\title{
INTRODUÇÃO
}

Este texto surge de nosso encontro na disciplina Ciência, Tecnologia e Movimentos Sociais durante o segundo semestre de 2008 no Instituto de Geociências da UNICAMP. Este curso foi oferecido por primeira vez no segundo semestre de 2007. No final de 2006, havia uma demanda pelo oferecimento de mais disciplinas eletivas para a graduação em Ciências da 
Terra (modalidade Geografia, entre as quais a de Movimentos Sociais) e ao mesmo tempo, no Programa de Pós-Graduação em Política Científica e Tecnológica (multidisciplinar) vários alunos estavam trabalhando com temas que exigiam conhecimentos relativos à teoria e história dos Movimentos Sociais. Como eram disciplinas oferecidas pela primeira vez, foram abertas poucas vagas (30 para graduação e 10 para a pós). Com a eclosão do movimento estudantil durante o primeiro semestre de 2007 , o número de alunos de toda a UNICAMP, que solicitaram matrícula nessa disciplina foi enorme e a pedido do Coordenador de Graduação de Curso, autorizei a matrícula de todos os solicitantes que fossem alunos regulares da universidade. A maior de nossas salas foi utilizada para isso e a experiência, ainda que um pouco anárquica foi extremamente produtiva e a presença de alunos estrangeiros de intercâmbio nas duas versões $\mathrm{e}$ filhos dos que viveram esse período de diferentes perspectivas enriqueceu o curso. Ao refazer o programa para sua versão 2008, tive que incluir um conto de Andersen, pois ao utilizar um artigo de jornal de Otávio Velho na Folha de São Paulo, descobri que entre os cerca de 90 alunos presentes, somente dois (maiores de 45 anos) conheciam esta história. Ao mesmo tempo, as comemorações dos 40 anos de 1968 permitiram a reedição de uma enorme bibliografia, filmes e debates sobre o tema. O objetivo da disciplina, desde sua primeira versão foi através de leituras, filmes, relatos, debates, fichamentos, resenhas e trabalhos em grupo (onde o tema era a análise de algum movimento social, utilizando alguma das teorias apresentadas escolhidas pelo grupo e com forma livre de apresentação, recursos audiovisuais, falas, textos, pocsias, ou o que fosse escolhido). O período analisado foi o que se inicia no póssegunda guerra mundial e as teorias discutidas (clássicas e contemporâncas) partem da Escola de Chicago onde surge o conceito de movimentos sociais e das sociologia do ator de Friedman e Touraine, até autores mais atuais².

\footnotetext{
2 Já na primeira, mas principalmente na segunda versão do curso, ao responder as perguntas dos alunos, a professora, nascida no babyboom do pós-guerra, c que ingressou na Universidade de São Paulo cm 1968, foi para o Chile em 1969 c para a Sućcia em 1973 retornando ao Brasil somente cm 1980, percebcu, que estava relatando experiências vividas, no Brasil, Chile c Europa nestes quarenta anos.
} 
Os movimentos sociais que emergem com toda força nos últimos anos num contexto de redemocratização e agora com a vitória de Barack Obama, nasceram e cresceram nos anos negros da Guerra Fria após a II Guerra Mundial, seja em países democráticos seja em regimes totalitários, tanto nos países ocidentais, como na Europa, Àsia c América Latina. Sua "demonização" pela grande mídia controlada por enormes empresas, das quais darei como exemplo no Brasil a revista Veja e os canais abertos da Rede Globo, ou o poder de Sílvio Berlusconni na Itália associada, a FOX nos Estados Unidos e muitos outros, associado ao interesse de muitos alunos pelos temas de gênero, economia solidária, meio ambiente e formas alternativas de desenvolvimento e de construção de conhecimento é que surgiu a necessidade de criar um espaço onde não só se aprendessem teorias, mas se compreendesse o contexto em que elas surgiram e aprendessem a utilizá-las para analisar seus temas de pesquisa, entendendo não só a história de nosso país, como do mundo. Os temas abordados foram bastante amplos, mas a metodologia foi a de cruzar os diversos olhares e opiniões sobre temas da atualidade: tais como as formas de organização dos movimentos urbanos c rurais, autonomia, organizações locais, nacionais e internacionais, movimentos libertários: (direitos civis, feministas, ecologistas, estudantis e pela paz), economia solidária / economia social e o debate sobre a apropriação social de ciência e tecnologia.

Foi de nosso encontro neste curso, que inventamos juntas este trabalho. Foi após as duas aulas sobre 1968 no Brasil que Elaine propôs o artigo conjunto e criamos este resumo. Após assistir Hair e $O$ Ano em que meens pais sairam de férias, Leda teve que mergulhar em suas memórias e entender porque por muitos anos, depois de voltar ao Brasil, não conseguia passar por lá, ou visitar o Chile (a trabalho) quase dez anos após a redemocratização, ou a Lisboa da Revolução dos Cravos (o início do fim das ditaduras européias) e a Berlim do Muro visitadas durante a década de 70 e revisitadas no início de 2008. No entanto, o que mais impressionou foi a perda da memória e a Leda teve que percorrer todo o século $\mathrm{XX}$ para responder as perguntas que surgiram na sala de aula. Ao contar piadas da época do FEBEAPÁ de Stanislaw Ponte 
Preta, ninguém havia ouvido falar de Antigona c contar que o DOPS ${ }^{3}$ foi prender o Sófocles não era piada para ninguém. Uma aluna da Alemanha Ocidental achava que filmes como $A$ Vida dos Outros ocorriam somente na Alemanha Oriental e nunca havia assistido Os Anos de Clumbo ou lido algum livro de Gunther Grass. Farenlbeit 451 de Trufaut era um desconhecido, a Guerra do Vietnã estava esquecida, a não ser nas versões de Rambo e da literatura brasilcira. Nossos clássicos eram apenas alguma coisa chata que se lê para o vestibular.

Aqui surgiu a hipótese de que a revolução conservadora que se iniciou durante os anos 70 e cujo primeiro experimento foi o Chile de Pinochet, que associou ditadura e recessão e mais de dez anos sem noite (toque de queda), o Prêmio Nobel a Milton Friedman, os governos Reagan e Tatcher promovendo o Estado Mínimo c o ataque frontal aos sindicatos e aos direitos sociais, hoje nos parece que um de seus efeitos mais deletérios foi a internalização dos valores do neolaisserfaire e a perda de memória causada pela reificação do novo (GITAHY, 2000). Como em um filme já visto, se repete a disputa entre os "capitães das finanças" c os "capitães da indústria", durante a Segunda Revolução Industrial saindo desta vez vitoriosos os primeiros que desta vez se transformaram em nossos "capitães das consciências" (GITAHY, 1992) através da perda da memória.

Assim o objetivo neste artigo é analisar, seja a partir da bibliografia utilizada, como de nossa convivência no curso entendido como um espaço de reflexão c debate, hoje tão escassos no ambiente universitário, a relação entre o hoje e esse ontem de quarenta anos atrás.

\section{E A GUERRA DA MARIA ANTÔNIA}

"Quarenta anos depois do incêndio caminho devagarinho por essa rua (Maria Antônia) boje pacificada tentando recollher algum vestigio de

\footnotetext{
${ }^{3}$ O Departamento de Ordem Politica e Social (DOPS) foi o órgão do governo brasileiro criado durante o Estado Novo, cujo objetivo era controlar e reprimir movimentos politicos e sociais contrários ao regime no poder.
} 
nossa presença. Não o resgate institucional, o memorial de resistência, mas o calor de um agora que bá quarenta anos virou ontem e ainda lateja.

Éramos tantos, éramos fortes, éramos loucos de paixão $\mathrm{c}$ fé. Mas o muro se erguia, a arma aprumava mira e a brutalidade se tornava lei para derramar a céu aberto o nosso sanguc. Vejo em cada nesga de cimento, pedra c porta nossa cara ainda fresca de tempo. Os que sobrevivemos e os que foram colhidos pela morte aqui mesmo. Vejo todos. Um por um...

Zé Arantes discursa, os imensos olhos negros brilhando como luas. Chico(Buarque de Holanda) compõe no bar da quitanda entre uma batida de coco e uma de maracujá. Renata (Souza Dantas) tenta decorar falas de "Os Fuzis da Senhora Carrar" para o espetáculo que o TUSP vai estrear. Aloysio (Nunes Fereira Filho), primeiro da classe, de muita ação e pouco falar, sobe no carro de som e troveja, o megafone a ampliar a já possantissima voz. Benê monta o roteiro da passeata enquanto passa slides de Renoir num mocó do infinito Copan.

Tudo ainda acontece. Romances nascem e morrem. A cara dada pra bater. A franqueza. O destemor e o mofo das celas. $O$ hino nacional cantado no Dops para aqueles antropóides. Um amasso cmbaixo de ponchos. Um beijo atrás da coluna. Alguém de porre no bar da esquina com dor de cotovelo, alguém de porre no bar da esquina celebrando novo amor.

Tenho prova com Ruth Cardoso dentro de minutos e tento estudar Levi Strauss no saguão. Inútil. Entregam-me um panfleto contra o ministro da justiça (Gama e Silva), outro contra a Guerra do Vietnã e um saquinho de bolinhas de gude para fazermos cscorregar os cavalos da polícia montada 
no comício da São João. Pelo buraco do elevador escalo o telhado $\mathrm{c}$ me junto à comissão de segurança, que tirita de frio há dias esperando a invasão. Del, $A b \hat{c}$, Lauri, Oscar, Yara, Lúcia, Tereza Cristina, Walnice, Lobão, Leda, Perrone, Angela, Zé Au, André, Bento, Célia, Marias, Josés e Joões estão todos aqui, dentro de mim, diante de mim, sonoros, vivos, meninos..." (Consuelo de Castro, 2008)'

A questão suscitada em todo mundo pelo ano de 1968, foi porque tantos jovens, de diferentes países, formações e histórias de vida foram para as ruas compartindo emoções e desejos comuns apesar da diversidade de suas experiências e discursos. De acordo com Kurlansky (2005), o ano de 1968 foi um ano muito diferente de qualquer outro, por conta das suas particularidades, lutas e mudanças num período em que nações e culturas ainda eram separadas. Para o autor, único em 1968 foi o fato de que as pessoas rebelaram-se $\mathrm{em}$ torno de questões disparatadas que tiveram em comum apenas seu desejo de se rebelar, suas idéias sobre como fazer isso, uma sensação de alienação da ordem estabelecida e um profundo desagrado pelo autoritarismo, sob qualquer forma. Os líderes rejeitaram a maioria das instituições, dos líderes políticos e dos partidos políticos.

De acordo com a Revista Ultimato (2008) valores como generosidade, humanismo, ecologia e nacionalismo foram alguns dos conceitos valorizados por este movimento contestatório de 68 , verdadeira antecâmara do que assistiríamos nos anos 70 e 80 . Para compreender a importância histórica de 1968, a revista reúne um conjunto de depoimentos de diversos intelectuais brasileiros e estrangeiros, tais como:

\footnotetext{
"Consuclo de Castro é dramaturga e escreveu, entre outras obras "A Prova de Fogo", que se passa na Maria Antônia. O Final do texto, dedicado a José Dirceu diz: "Você ainda fala cm vitória no topo do Municipal. Eu ainda uso a mesma calça Lee, a mesma bota topa tudo e ainda esqueço o saquinho de bolas de gude no balcão do seu Joaquim. Ainda sou tua melhor amiga. Como insisti que você me chamasse quando te visitei no presídio de Itaipu."
} 
"1968 foi, antes de mais nada, um ano de revolta estudantil e juvenil, numa onda que atingiu paises de naturezas sociais e estruturas tão diferentes como Egito, Estados Unidos, Polônia. O denominador comum é uma revolta contra a autoridade do Estado e da família." (Edgar Morin, 87 anos).

“1968 se mostrou uma revolução subterrânea que reformou as pequenas csferas do trabalho, da familia e da escola. Transformou nossa maneira de falar, de sentir. Foi uma verdadeira liberação dos costumes [...] Maio de 68 marcou o início da pós-modernidade."(MiCnII. MAFilisoli, 64 anos).

"Em maio de 1968 tomou-se a palavra como tomou-se a Bastilha em 1789."(Michael, de Certieau, 61 anos).

"[Em 1968] o movimento "hippie" estava no auge, com seu lema 'faça o amor, não faça guerra'. $A$ juventude recusou o mundo legado por seus pais, encharcado do sangue de duas guerras mundiais, da tensão da Guerra Fria e do assassinato em massa na Guerra do Victnã. E o caminho que encontrou para seu protesto foi redescobrir a natureza, a liberdade das relações sexuais, o sexo sem conseqüências, garantido pela pílula anticoncepcional que as mulheres começaram a tomar para evitar a gravidez indesejada [...] O ano de 1968 foi marcado pela rejeição a todo autoritarismo e totalitarismo, afetando a interlocução c o diálogo entre gerações c estamentos da sociedade."(MARIA CI.ARA BINGEMER, 58 anos, teóloga e professora da USP).

"Os eventos do Maio de 68 na França podem ser interpretados como o estopim de uma série de transformações politicas e comportamentais ocorridas na segunda metade do século 20 e que tiveram como eixos centrais: o desejo de liberdade, a busca de prazer sem limite, a recusa de qualquer forma de controle $\mathrm{e}$ de autoridade $\mathrm{e}$ a defesa da igualdade entre homens e mulheres (...) Para os 
jovens estudantes franceses do Maio de 68, liberdade, felicidade e prazer eram elementos inscparáveis de uma revolução cujo lema cra: 'É proibido proibir'."(MIRIAM GOLDENBERG, antropóloga e professora da UFRJ).

"[Em maio de 1968] não conhecíamos a AIDS nem degradações climáticas nem provações da globalização, do desemprego. Éramos prometéicos. Tudo parecia possível. $\mathrm{O}$ futuro nos pertencia. [...] É muito mais angustiante ser jovem hoje do que há 40 anos. Mas quem tem vontade de se revoltar se revolta! [...] Em todo caso, 1968 não deve ser visto como modelo. Retenham simplesmente que existem momentos históricos $\mathrm{cm}$ que alguma coisa explode - um desejo de fazer avançar, de transformar a sociedade -, c que isso pode funcionar." (DANIEl. COHN-BLNDrI, 63 anos - deputado no Parlamento Europeu, do Partido Verde Alemão e lider do movimento de maio na Franca).

Em a Era dos Extremos (1995), Eric Hobsbawm associa este momento às transformações sociais do pós-guerra em dois capítulos que se chamam: A revolução social e A revolução cultural. No filme Os Sonhadores de Bertollucci, fica clara a opção entre o implode ou explode.

No Brasil, o golpe militar de abril de 1964 inaugura um período autoritário, após um período de pouco mais de dez anos de regime democrático e em plena explosão de um movimento cultural que atinge a música, o teatro, o cinema e a cultura em geral. A queima do prédio da $\mathrm{UNE}^{5}$ logo após o golpe seguida de prisões, tortura e exílio dos principais

\footnotetext{
${ }^{5}$ União Nacional dos Estudantes (UNE) foi fundada $\mathrm{cm} 1937 \mathrm{c}$ ao longo de seus 70 anos, marcou presença nos principais acontecimentos políticos, sociais e culturais do Brasil. Desde a luta pelo fim da ditadura do Estado Novo, desenvolvimento nacional, a exemplo da campanha do Petrólco, os anos de chumbo do regime militar, as Diretas Já e o impeachment do presidente Collor. Da mesma forma, foi um dos principais focos de resistência às privatizações e ao neoliberalismo que marcou a Era FIC. Disponivel em: <http://wwwune.org.br/>. Acesso cm: 27 out. 2008.
} 
políticos inaugura o período. Se a intenção dos primeiros governos militares foi o de promover uma nova constituição (a de 1967) a disputa entre os setores mais ou menos duros dentro das Forças Armadas vai culminar no AI$5 \mathrm{~cm}$ dezembro de $1968^{6}$. Já o movimento estudantil, começa a se reorganizar a partir de 1966, em torno das lutas pela Reforma Universitária. Na USP e especialmente na Faculdade de Filosofia, Ciências e Letras, c em outras universidades, a discussão da Reforma Universitária se dá em comissões paritárias de alunos e professores, no caso da Faculdade de Filosofia escolhidas pela Congregação para discutir a reforma universitária c redigir um documento que propões uma universidade que fosse capaz de ser crítica de si mesma. O Professor Antônio Cândido foi o relator dessa comissão e várias dessas propostas foram implementadas posteriormente.

Se a morte do estudante Edson Luís, secundarista assassinado pela polícia ao reivindicar melhores refeições $\mathrm{em}$ um restaurante universitário no Rio de Janeiro foi o ato de violência que sensibilizou a opinião pública para a luta estudantil que culmina com a passcata dos cem mil, no segundo semestre a política estudantil de 1968 teve seu ponto mais crítico e se transferiu para São Paulo. Segundo Valle (1999) a longa ocupação pelos estudantes da Filosofia da USP, na Rua Maria Antônia, aguçou a tradicional rivalidade com o centro

\footnotetext{
${ }^{6} \mathrm{O}$ Ato Institucional Nímero Cinco - Al-5 foi o quinto de uma série de decretos cmitidos pelo regime militar nos anos seguintes ao Golpe militar de 1964 no Brasil. Redigido pelo Presidente Artur da Costa e Silva em 13 de de\%embro de 1968. Fechou o Congresso Nacional por pra\%o indeterminado; decretou o recesso dos mandatos de senadores, deputados e vereadores. Estes ainda continuaram a receber parte fixa de seus subsidios; autorizou, a critério do interesse nacional, a intervenção nos estados e municípios; tornou legal legislar por decreto-lei; autorizou, após investigação, decretar o confisco de bens de todos quantos tenham enriquecido, ilicitamente, no exercício de cargo ou função pública, inclusive de autarquias, cmpresas públicas e sociedades de cconomia mista, sem prejuizo das sanções penais cabiveis; O P'residente da República, cm qualquer dos casos previstos na Constituição, poderá decretar o estado de sítio e prorrogá-lo, fixando o respectivo prazo; suspendeu a possibilidade de qualquer reunião de cunho politico; recrudesceu a censura, determinando a censura prévia, que se estendia à música, ao teatro c ao cinema de assuntos de caráter político; suspendeu o babeas corpus para os chamados crimes politicos. Disponivel cm: <http://pt.wikipedia.org/wiki/Ato_Institucional_N\%C3\%BAmero_ Cinco>. Acesso em: 26 out. 2008.
} 
da direita paulista, a Universidade Mackenzie, que ficava na mesma rua. A repressão explorou essa rivalidade, com a contribuição do Comando de Caça aos Comunistas (CCC), no Mackenzie, promovendo uma verdadeira batalha contra a Filo-USP. Deste choque resultou a morte do secundarista José Guimarães. Sob a direção de José Dirceu de Oliveira e Silva, presidente da União Nacional dos Estudantes de São Paulo (UEE-SP), os estudantes foram às ruas em grandes levas. De acordo com Ferraz (1988) o confronto cra de posições políticas não de Universidades. Os estudantes queriam a democratização da sociedade, portanto, lutavam contra a ditadura militar, c no plano mais específico contra o acordo MEC-USAID ${ }^{7}$, que não correspondia aos intercsses nacionais do país.

Desde junho, a Faculdade de Filosofia da USP, sediada na Rua Maria Antônia, estava vivendo a experiência da ocupação. O presidente do Grêmio da Filo-USP, Bernardino Figueiredo disse que essa nova forma de ação política visava a democratização da Universidade, transformando-a em centro de reunião, discussão política, mobilização e organização dos universitários e secundaristas para garantir a continuidade do movimento.

Já o Mackenzie estava armado e com proteção de policiais, enquanto os alunos da Filosofia estavam sozinhos, em desvantagem. Chegou então o AI-5 que acabou com todas as garantias individuais. A Maria Antônia nos anos 60 vivia em constante ansiedade de transformações, mudanças de costumes, pensamentos e hábitos, foi um ano de poesia e revolução cultural, pode-se dizer que foi um:

... forte movimento cultural: cinema novo, grupos de teatro Arena e oficina, as publicações da civilização, da Brasiliense, as revistas especializadas, tudo com propostas

\footnotetext{
${ }^{7}$ MEC USAID é a fusão das siglas Ministério da Educaf̧ão (MEC) c United States Agency for International Development (USAID). Simplesmente conhecidos como acordos MEC-USAID cujo objetivo era aperfeiçoar o modelo educacional brasileiro. Disponível em: <http://www.histedbr.fac.unicamp.br/navegando/glossario/verb_c_mec-usaid\%20.htm>. Accsso cm: 05 nov 2008.
} 
de renovação $\mathrm{e}$ de modernidade Mackenzie x Filosofia-USP. (FERRAZ, 1988, p. 228).

Um outro ponto importante segundo Cardoso (1988) é a questão do esquecimento e da memória que são duas variáveis importantes para lembrar sempre dos acontecimentos. Uma vez que os esquecimentos foram constantes, a documentação ficou clandestina, oculta, foram inúmeras destruições provocadas pelo terror da repressão. $\mathrm{O}$ acesso aos documentos se tornou muito peculiar. Essa preservação, às ocultas, da documentação torna o trabalho de recuperação de documentos também fragmentado. Nos modos de aproximação com os acontecimentos ocorridos em 68 e seus desdobramentos são absolutamente recorrentes imagens como esquecimento, silêncio, memória, recomposição, fragmentos, perda, vestígios e cacos. $\mathrm{O}$ estigma de 68 continua intacto, escuro, fechado, como o quarto de um falecido ilustre onde ninguém entra.

"Se bá razão para lembrar é que o silêncio e o esquecimento são as constantes da repressão dos últimos anos. É preciso furar o segredo e 0 pavor, fazer de recordaçoes dispersas a reflexão comum na consciência coletiva". (HERBERT, 1982, p. 32)

Segundo Cardoso (1988) o ano de 1968 foi o ano dos festivais de música popular, explosão da tropicália, surgimento de Caetano e Gil, mas também de muita repressão, prisões, mortes, desaparecimentos, exílio, clandestinidade, perseguição dos "suspeitos", tortura, perda e melancolia:

Desaparecidos - morte e sepultura. A impossibilidade da realização do ritual do luto - a sepultura - configura uma situação de perda em que não se consegue renunciar ao objeto perdido, o que produz a melancolia. (CARDOSO, 1988, p. 235)

Os acontecimentos de 68 foram inúmeros, tais como: reforma universitária, início das ações armadas e combate a subversão - Operação 
Bandeirantes $(\mathrm{OBAN})^{8}$, foram marcantes para a história do país, uma vez que não se tinha visto nada parecido antes. Um movimento que fez com que os estudantes lutassem pelas causas que desejavam e que percebessem que cra preciso ocorrer mudanças para que a situação fosse melhor no futuro. Muitos dos estudantes, por conta da participação no movimento, tiveram suas vidas comprometidas com a causa de todo o país e pagaram um preço alto por se envolver com os políticos e por reivindicar o que desejavam. Mas tinham um ideal de luta e isso fazia-os fortes.

Nos dias dois e três de Outubro de 1968 eclode a Guerra na Maria Antônia, mesmo dia em que os projetos de lei da reforma universitária são encaminhados ao Congresso. Incêndio $\mathrm{e}$ destruição seguidos de desocupação e abandono do prédio. Rojões, paus e pedras (Filosofia-USP) x Revólveres, rifles, metralhadoras $\mathrm{c}$ bombas Motolov (Mackenzic). Secundaristas estavam fazendo pedágio para arrecadar dinheiro para o $30^{\circ}$ Congresso da UNE quando foram atacados por estudantes da Mackenzie. Foi dessa forma que a guerra começou.

A Faculdade de Filosofia, Ciências e Letras foi esvaziada. De acordo com Chaui (1984), scus ocupantes, submetidos ao "corredor polonês", são lançados em camburões, rumo ao DOI-CODI", ao DOPS e à OBAN. A mando do governador $A$ breu Sodré que garante ter recebido a ordem de invasão do Ministro Gama e Silva. O Reitor Mário Ferri, assegura ter-se recusado a obedecer à ordem do governador. Talvez tenha sido uma ação voluntária e espontânea das "forças da ordem".

Assim, a Guerra da Maria Antônia, começou porque estudantes da Mackenzic juntamente com o Comando de Caça aos Comunistas - CCC travaram uma batalha com os alunos da Filosofia da USP. Esses alunos estavam

\footnotetext{
${ }^{8}$ A Operação Bandeirante - $O B A N$ foi um centro de informações, investigações e de torturas montado pelo Exército do Brasil em 1969, que a coordenava e integrava as ações dos órgãos de combate às organizações armadas de esquerda que tinham por objetivo confrontar o regime ditatorial que vigorava desde 1964 no Brasil.

${ }^{9} \mathrm{O}$ Destacamento de Operaçōes de Informafões - Centro de Operaşões de Defesa Interna (DOI-CODI) foi o órgão de inte ligência e repressão do governo brasileiro durante o regime inaugurado com o golpe militar de 31 de março de 1964, os chamados "Anos de Chumbo".
} 
fazendo um pedágio para arrecadar verba para o $30^{\circ}$ Congresso da UNE que foi em Ibiúna. Esses processos foram apenas o começo, o final é a queima de livros e documentos, tortura e prisão de estudantes que lutavam pelos seus ideais de vida. Além da concretização dessa tendência, verificou-se também uma resistência muito grande ao período da ditadura militar que usou a violência como diálogo. (VALLE, 1999) ${ }^{10}$

\section{BIBLIOTECAS, MÍDIA, HISTÓRIA E MEMÓRIA}

Se os momentos de eclosão da violência e do totalitarismo evocam a queima de livros e bibliotecas, a década de sessenta vai inaugurar a emergência dos meios de comunicação de massa, especialmente com o advento da televisão que trazia para nossas telinhas as cenas ao vivo da Guerra do Vietnã, da chegada do Homem à Lua e fínalmente a Copa do Mundo de 70, que foi a primeira a ser transmitida ao vivo (antes era acompanhada pelo rádio). $\mathrm{O}$ advento da chamada Sociedade da Informação vai paradoxalmente inaugurar o que Castells (1999) chama da oposição bipolar entre a Rede e o Ser, ou a relação esquizofrênica entre a função e o significado, o que para Max Weber seria a hegemonia da razão proposital instrumental. Perdidos em um mar de informações, cada vez é mais difícil preservar a memória entre as várias gerações. Os livros mais antigos ou clássicos desaparecem das bibliotecas (dificuldade de manutenção) estão sujos ou não há espaço. Os contos de fada se reduzem aos desenhos animados da Disney e os dados de pesquisa são considerados velhos porque há que publicar no último número da revista classificada como Qualis $\mathrm{A}$ e não há tempo para o trabalho conjunto, perdendo-se a capacidade de reflexão.

\footnotetext{
${ }^{10}$ No livro de Valle (1999), existe um capitulo denominado " $A$ guerra da Maria Antônia e a violência: o movimento estudantil, o governo e a imprensa". Nesse capitulo, cla consegue de forma clara, colocar a opinião de todas as partes cnvolvidas nessa luta, assim como a forma que a imprensa divulgava os fatos ocorridos.
} 
Ao tentar recuperar a memória destes anos tratamos de caminhar $\mathrm{em}$ outra direção e tentar mostrar como é importante pensar em como os documentos nos ajudam a reconstruir a história. Dessa forma, seria necessário obter melhores formas de seleção, armazenamento e recuperação das informações e dos documentos. Sendo assim, a informação e a memória serão mais valorizadas.

Atualmente, nossa sociedade encontra-se refém de um tipo de ideologia que reifica o novo (entendido como melhor e mais eficiente, seja lá isso o que for), a competição e o individualismo, No entanto há forças e movimentos sociais que contestam esses valores e que podem nos levar a uma sociedade mais solidária, menos desigual c que respeite as diferenças, o que só é possível a partir de formas de gestão mais democráticas e pluralistas.

\section{REFERÊNCIAS}

CARDOSO, Irene de Arruda Ribeiro. Os acontecimentos de 1968: notas para uma interpretação. In: SANTOS, Maria Cecilia Loschiavo dos. Maria Antônia: uma rua na contramão. São Paulo: Nobel, 1988. p. 222-228.

CASTELLS, Manuel. O poder da identidade. 6 ed. São Paulo: Paz c Terra, 1996.

CASTRO, Consuelo. Quarenta anos, aqui, agora. e-mail dedicado a José Dirceu na lista "1968 Quarenta Anos".

CHAUÍ, Marilena. O dia em que a Maria Antônia pegou fogo, Ciência Hoje, v. 3, n. 13, jul./ago. 1984.

FERRAZ, Lauro Pacheco de Toledo. Maria Antônia/ 68: o outro lado da rua. In: SANTOS, Maria Cecília Loschiavo dos. Maria Antônia: uma rua na contramão. São Paulo: Nobel, 1988. p. 229-239.

HERBERT, Daniel. Passagem para o próximo sonho. Rio de Janeiro: CODECRI, 1982. 
Hobsbawn, Eric. A Era dos Extremos: o breve século XX (1914-1991). Cia. das Letras, São Paulo, 1995.

GITAHY,Leda. Na direção de um novo paradigma de organização industrial? In: ENCONTRO ANUAL DA ANPOCS, 16., 1992, Caxambu. Anais... Caxambu: Anpocs, 1992.

GITAHY, Leda. A Nenv Paradigm of Industrial Organization. Comprehensive Summaries of Uppsala Dissertations from the Faculty of Social Sciences 93: Acta Universitatis Upsaliensis, Uppsala. 2000.

GOHN, M. G. Teorias dos movimentos sociais: paradigmas clássicos e contemporâneos. 5 ed. São Paulo: Edições Loyola, 2006.

KURLANSKY, Mark. 1968: o ano que abalou o mundo. Rio de Janeiro: José Olympio, 2005.

REVISTA ULTIMATO. A contagem regressiva de 1968: o ano que não terminou, Revista Ultimato, Edição especial, n. 313, jul./ago. 2008. Disponível em: <http://www.ultimato.com.br/ $? \mathrm{pg}=$ show_artigos $\&$ secMestre $=2198 \& \mathrm{sec}=2226 \&$ num_edicao $=313 \mathrm{>}$. Acesso em: 26 out. 2008.

VALLE, Maria Ribeiro do. 1968 o diálogo é a violência: movimento estudantil c ditadura militar no Brasil. Campinas: Editora da Unicamp, 1999.

PREITE SOBRINHO, Wanderley. Luta contra a ditadura militar marca movimento estudantil no Brasil em 1968, Folha on Line, 30 abr. 2008. Disponivel em: <http://wwww1.folha.uol.com.br/folha/brasil/ ult96u383111.shtml>. Acesso cm: 15 out. 2008. 


\section{SOBRE OS AUTORES}

Antônio de Pádua de Lima Brito è graduado $\mathrm{em}$ economia pela Universidade Federal de Pernambuco (UFPLE) e mestre em sociologia pela Universidade Estadual de Campinas (Unicamp). Foi técnico da Superintendência do Desenvolvimento do Nordeste (SUDIENIE) de1995 a 1996, consultor do Ministério da Educação (MIE) entre 1997 e 2001, e Coordenador de Planejamento do Programa Cultura Viva do Ministério da Cultura (MinC) de 2004 a 2006. Atualmente, trabalha no Ministério do Desenvolvimento Social (MDS) na gestão de condicionalidades do Programa Bolsa Família (l'BI).

Carlos Alberto Dória é doutor em Sociologia pela Universidade Estadual de Campinas (Unicamp) e atualmente pesquisador-colaborador do IF CII-Unicamp, com bolsa de P'ós-doc financiada pela Capes. Autor do livro Os federais da cultura (Biruta, 2003), sobre as políticas públicas para a cultura no Brasil.

Elaine Hipólito dos Santos Costa é mestranda na Universidade Estadual de Campinas (Unicamp) e pesquisadora do Grupo de $\lambda$ nálise de Politicas de Inovação-G $A$ P'J. Seu tema de trabalho se volta para os l'luxos de Informação, Cadeia Produtiva do Lixo, Economia Solidária e 'lecnologia social $\mathrm{em}$ cooperativas populares. $\Lambda$ tua na área de Ciência da Informação.

Flávio Mendes é mestre em Sociologia pela Universidade Estadual de Campinas (Unicamp) com a dissertação Do consenso ao dissenso: o Movimento Bolivariano e o ressurgimento da política na Venezula (2010). Atualmente é doutorando $\mathrm{cm}$ Sociologia na mesma instituição. Leda Maria Caira Gitahy é doutora em Sociologia pela Uppsala Universitet (2000). Autora, dentre outras obras, de Novas tramas produtivas: tuma discussão teórico metodológica (SENAC, 2005) c $A$ new paradigm of industrial organization: the diffusion of technological and managerial inovations in the brazilian industry. Uppsala: (Acta Universitatis Upsalientis, 2000). Atualmente è Professora Doutora da Universidade Estadual de Campinas (Unicamp) e membro da Associación Latinoamericana de Sociologia Del'Trabajo. Atua na ärea de Sociologia, com enfase cm Sociologia do Desenvolvimento, sobretudo nos temas: paradigmas tecnológicos, flexibilidade da produção, cadcias de produção e indústria no Brasil.

Marcelo Ridenti é doutor cm Sociologia pela Universidade de São Paulo (USP). Autor, cntre outras obras, de Em busca do povo brasileiro: artistas da revoluf̧ão, do CPC à era da tv (Record, 2000), O fantasma da revoluf̧ão brasileira (Ed. UNESP, 1993), Classes sociais e representaf̧ão (Cortez, 1994). É professor titular de Sociologia na Universidade Estadual de Campinas (Unicamp). 
Atualmente, integra a Coordenação de Ciências Humanas e Sociais na Fundação de Amparo à l'esquisa do Estado de São Paulo (FAPFSI'). l'oi Secretário Executivo da Associação Nacional de Pós-Graduação e P'esquisa em Ciências Sociais (ANPOCS, 2004-2008). 'lem experiência na área de Sociologia, atuando principalmente nos seguintes temas: cultura/ arte e politica/ esquerda brasileira/ intelectualidade brasileira/ pensamento marxista/ ditadura militar brasileira/ anos 1960 .

Marcos Napolitano é doutor cm História Social pela Universidade de São Paulo (USl'). 1985). É autor de $A$ sincope das idéias: a questão da tradição na misica popular brasileira (Fundação Perscu Abramo, 2007) c Seguindo a canção: engajamento politico e indistria cultural na MPB - 1959/ 1969 (AnnaBlume/F $\Lambda$ PESP, 2001), entre outros titulos. Atualmente ć professor de IIistória do Brasil Independente na USP, docente-orientador no Programa de História Social da USP e professor visitante do Instituto de $A$ ltos Estudos da $A$ mérica Latina (IHE $A L$ ) da Universidade de Paris III e do Programa de I Iistória da UIFl'R. É assessor ad-hoc da Fundação de $A$ mparo à P'esquisa do Estado de São Paulo e do CNP'q. Especialista no periodo do Brasil Republicano, com ênfase no regime militar e na área de história da cultura e nas relações entre música popular c politica.

Mariângela Ribeiro ć mestre em Sociologia pela Universidade Estadual de Campinas (Unicamp) com dissertação intitulada $A$ canção como narrativa: o discurso social na MPB. Atualmente trabalha com pesquisa e gestão cm ONGs que atuam com Dircitos Humanos, Justiça e Segurança, tendo feito uma formação permanente em Mediação de Conflitos cm Madrid, Espanha, como bolsista da Fundación Carolina. Desenvolve também consultorias no campo de políticas públicas para organismos internacionais $\mathrm{e}$ governos.

Miliandre Garcia ć doutora em I Iistória Social pela Universidade Federal do Rio de Janciro com a tese On vocês mudam, on acabam: teatro e censura na ditadura militar (1964-1985). É autora do livro Do teatro militante à canção engajada: a experiència do CPC da UNE (1958-1964) (Iiditora Fundação Perseu $\Lambda$ bramo, 2007). Em 2008 realizou trabalho de pesquisa sobre censura teatral no período entre ditaduras na Biblioteca Nacional, como pesquisadora desta instituição. Atualmente realiza pós-doutorado na Universidade de São Paulo (USP'), com pesquisa em andamento sobre políticas culturais no regime militar e ênfase nos impasses entre uma categoria de artistas c o regime autoritírio. Scus temas de enfoque são arte c cultura, engajamento artístico, ditadura militar, censura c autoritarismo, resistência cultural.

Michael Löwy é doutor em Sociologia pela Sorbonne (1964), sob orientação de Jucien Goldmann. Vive em laris desde 1969, onde trabalhou como diretor de pesquisas no CNRS (Centre National de la Recherche Scientifique). Atualmente coordena seminários na École des Hautes litudes en Sciences Sociales (IEHISS). Scus escritos foram traduzidos cm vinte e seis idiomas. É autor, dentre outras obras publicadas no Brasil, de As aventuras de Karl Marx contra - Barão de Mänchbausen (Cortě, 2000), Revolla e melancolia : o romantismo na contramão da modernidade (Vozes, 1995), Aviso de incêndio : uma leitura das teses " sobre o conceito de bistória » de IValter Benjamin

Temáticas, Campinas, 19(37/38): 249-251, jan./dez. 2011 
(Boitcmpo, 2005), Estrela da manbãa: surrealismo e marxismo (Civilização Brasilcira, 2002) c Franz Kafka: sonbador insubmisso (Azougue, 2005).

Renato Dagnino é professor titular na Universidade listadual de Campinas (Unicamp) e tem atuado como professor visitante nas äreas de Lstudos Sociais da Ciência e 'Tecnologia e de Política Científica e l'ecnológica em várias universidades latino-americanas na área dos Estudos Sociais da Ciencia e lecnologia e da Politica Cientifica e 'lecnológica. É engenheiro, estudou Ciências I Humanas e Ĺconomia no Chile e no Brasil, onde se doutorou. Realizou pós-doutorado na Universidade de Sussex, na Inglaterra. Lintre seus mais recentes livros cstão Ciència e Tecnologia no Brasil: o processo decisório e a commnidade de pesguisa (EdUnicamp, 2007); Neutralidade da Ciència e Determinismo Tecnologico (EdUnicamp, 2008), Possui várias publicafões, entre as quais destacamosTecnologia Social: ferramenta para construir outra sociedade (Cia de Comunicação, 2009); Estudos Sociais da Ciência e Tecnologia e Polifita de Ciência e Tecnologia: abordagens alternativas para uma nova América Latina (Pedro\&João Lditores, 2009).

Rodrigo Czajka ć doutor $\mathrm{cm}$ Sociologia pela Universidade Lstadual de Campinas (Unicamp) e professor Adjunto de Sociologia do Instituto de I Iumanidades da Universidade Federal dos Vales do Jequitinhonha e Mucuri (UFVJM), campus Diamantina (MG). Atualmente é pós-doutorando $\mathrm{cm}$ Sociologia junto ao Instituto de Fïlosofia c Ciências H Iumanas da Unicamp. Tem experiência na área de lïlosofia e Sociologia com ênfase $\mathrm{em}$ Sociologia da Cultura e atua principalmente nos seguintes temas: cultura e sociedade, indústria cultural, intelectuais, csquerdas c resistência cultural.

Rosane Pires Batista é professora de Metodologia Cientifica da Universidade Paulista (UNIP), Mestre em Sociologia pela Universidade de São l’aulo (USP) e doutoranda cm Sociologia pela Universidade Estadual de Campinas (Unicamp) onde desenvolve pesquisa na área de Sociologia da litcratura. 
